\title{
Posttraumatic Stress Disorder in the General Population After Mass Terrorist Incidents: Considerations About the Nature of Exposure
}

\author{
By Sandro Galea, MD, DrPH, and Heidi Resnick, PhD
}

FOCUS POINTS

- Terrorist events are shared traumatic experiences that may result in substantial psychological consequences in the general population.

- After a terrorist event, there may be posttraumatic stress symptoms among persons who are not traditionally considered "exposed" to the disaster.

- Data from studies in the aftermath of the September 11,2001 , attacks suggest that posttraumatic stress among persons living in New York City was similar among those who were and those who were not directly exposed to the attacks.

- In a densely populated urban area, exposure to a terrorist event may be complex and may include the perception of personal threat arising from watching a disaster unfold on television.

\section{ABSTRACT}

Epidemiologically, disasters represent multiple forms of possible exposures, including exposure type (eg, natural versus human-made), intensity, and duration. It has been suggested that the consequences of human-made disasters (eg, terrorist incidents) may be more severe than those of natural disasters; recent evidence suggests that there may be a high prevalence of posttraumatic stress disorder (PTSD) among both direct survivors of such attacks and in the general population. Several studies after the September 11, 2001, terrorist attacks found that the prevalence of PTSD was higher in New York City than it was in the rest of the US and that there was a substantial burden of PTSD among persons who were not directly affected by the attacks. This raises important questions about the meaning of "exposure" to a disaster. Using data from an assessment of PTSD in the first 6 months after September 11th we considered the nature of the PTSD experienced by persons who were not directly affected by the September 11 th attacks. These data suggest that persons in the general population may have clinically important posttraumatic stress symptomatology after a mass terrorist incident. Future research should consider mechanisms through which persons in the general population may be at risk for PTSD after such incidents.

CNS Spectr. 2005;10(2):107-115

\section{INTRODUCTION}

Traumatic event experiences are relatively common. More than two thirds of persons in the general population may experience a significant traumatic event at some point in their lives and up to one fifth may experience such an event in any given year. ${ }^{1-5}$ Although international data comparable to these United States data are limited, large proportions of populations in many countries worldwide have been exposed to terrorism, forced relocation, and violence suggesting that the overall prevalence of exposure to traumatic events worldwide may be even higher than it is in the US.-8

Disasters or experiences of mass trauma are one specific form of traumatic event experience that has received much attention lately due to the growing worry about terrorism. The prevalence of exposure to mass trauma is difficult to estimate. In one survey of

Dr. Galea is medical epidemiologist at the Center for Urban Epidemiologic Studies at the New York Academy of Medicine in New York City. Dr. Resnick is professor of clinical psychology at the National Crime Victims' Research and Treatment Center at Medical University of South Carolina in Charleston.

Acknowledgments: The authors would like to thank Ms. Melissa Tracy for analytic help and Ms. Emily Gibble for editorial assistance.

Dislcosure: Supported by grants from the United Way of New York City and The New York Community Trust (The September 11 Fund), the National Institute on Drug Abuse (R01 DA14219-01S1, R01 DA012801-03S1, R01 DA0170001A1, and R01 DA17020-01), The National institutes Health (1R01 DA131146, R01DA06534-11A2, R01 DA017642-01, R25 MH070552-01), and the National Institute of Mental Health of the National Institutes of Health (R01 MH66081-01 and R01 MH66391-01). This article was submitted on February 24, 2004, and accepted on November 1, 2004. Dr. Resnick has received grant support from the National Institute on Drug Abuse (R01 DA1158).

Please direct all correspondence to: Sandro Galea, MD, DrPH, Center for Urban Epidemiologic Studies, New York Academy of Medicine, 1216 Fifth Avenue, New York, NY 10029; Tel: 212-822-7378, Fax: 212-419-3612; E-mail: sgalea@nyam.org. 
US residents, $13 \%$ of the total sample reported a lifetime exposure to natural or human-generated disaster. ${ }^{9}$ In the National Comorbidity Survey, ${ }^{4}$ 18.9\% of men and $15.2 \%$ of women participants reported a lifetime experience of a natural disaster. Disasters are shared traumatic experiences, resulting not only in the direct impact related to the event itself but also in changes in many of the other factors (eg, social supports) that may shape the psychological sequelae of disasters. In the context of disasters there are several different forms of exposures possible. From an epidemiologic point of view, different intensity, duration, and type of exposure may all have different implications. Therefore, different disasters (eg, natural versus man-made) and different contexts (eg, dense urban area versus rural area) may have substantially different consequences. ${ }^{10}$ Terrorist attacks in turn are a particular form of human-made disasters. Recent high-profile terrorist attacks, including ongoing suicide attacks in Israel, the September 11, 2001, attacks on the World Trade Center in New York City, and the March 11, 2004, train bombings in Madrid have increased our awareness of the potential of terrorist attacks and suggest that a better understanding of the psychological consequences of terrorism may be in order.

Mass terrorist attacks are highly visible disasters that are designed to affect both those who are directly in the vicinity of the attacks and also persons in the population at large. Terrorist attacks may be associated with substantial consequences both among those who are directly as well as indirectly affected by the attacks. Persons who are directly affected by terrorist attacks are frequently referred to in the literature as "victims" of the event. This may include persons who were injured during the attack or, in some circumstances, bereaved family members of persons who died in the terrorist attack. The group of persons who are indirectly affected by terrorist attacks is harder to define. In the context of individual traumatic event experiences (eg, rape), relatives or close friends of the person who experienced the trauma may be considered indirectly affected. This concept becomes critical in the context of research about the consequences of terrorism in the general population. In mass terrorist attacks, the entire general population of an affected area may plausibly be considered indirectly affected even in the absence of direct witnessing or presence of disaster related losses. However, considering entire populations as potentially "exposed" to a terrorist event raises important nosologic questions about the meaning of exposure to traumatic event experiences. In this article, we will discuss key papers from the published literature that have considered the population burden of psychopathology after terrorist attacks. We do not aim this review to be comprehensive, but rather illustrative of the issues these studies raise. We refer the reader to other works for more comprehensive reviews. ${ }^{10}$ Subsequently, we present analyses from some of our own work after the September 11th terrorist attacks in New York City to further explore the nature of the general population exposure to such incidents. We focus this review on posttraumatic stress disorder (PTSD). Although we recognize that a range of psychopathology (eg, depression) may be importantly associated with disasters in general and terrorism in particular, we focus here on PTSD for two reasons. PTSD is the most commonly studied consequence of traumatic event exposure, and it is unique among psychiatric disorders in being linked to a specific traumatic etiology and as such, considerations regarding the nature of exposure in the general population after a mass terrorist attack are particularly important for the diagnosis of PTSD.

\section{POSTTRAUMATIC STRESS DISORDER IN THE GENERAL POPULATION AFTER ACTS OF MASS TERRORISM}

The literature on the psychological consequences of terrorism in the general population was sparse before the September 11th terrorist attacks. During the Oklahoma City bombing, 168 persons were killed, $>800$ people were injured and $>12,000$ persons were involved in the rescue efforts. ${ }^{11}$ In one survey of the Oklahoma City metropolitan area, ${ }^{12}$ $61.5 \%$ of adults reported experiencing at least one psychological symptom as a direct result of the bombing. Oklahomans compared with respondents in a control community also reported approximately twice the levels of stress, components of psychological distress, and intrusive thoughts related to the bombing site and these differences persisted into 1996, a year after the bombing. ${ }^{12}$ In another study ${ }^{13}$ that compared 472 community members divided in thre study groups (two from Oklahoma City and one from Lexington Kentucky) based on levels of exposure and proximity to the terrorist attacks,proximity to the attacks was a predictor of PTSD symptoms among those not directly exposed. Other studies ${ }^{14,15}$ after the Oklahoma City bombing documented posttraumatic stress symptoms among children who were indirectly exposed to the attacks.

The September 11th terrorist attacks presented a unique opportunity to systematically assess the psychological consequences of the attacks in the general population. The magnitude of the September 11th attacks and the subsequent anthrax mailings 
and economic downturn all suggested that the public mental health consequences of the attacks might be substantial. Soon after September 11th several research teams recognized that some of the key research questions emerging from the attacks were those pertaining to the general population. Several studies have since been published that provide insight into the burden of PTSD in the general population after a terrorist attack.

The first published study ${ }^{16}$ of reported psychological reactions and coping behaviors within a general national population sample following the September 11 th attacks involved a structured telephone interview with a national sample of 560 US adults within 3-5 days of the September 11th attacks. This study reported that $44 \%$ of their participants endorsed having experienced one or more PTSD symptoms since September 11th on a 5-item measure adapted from the PTSD Checklist (PCL). ${ }^{17}$ Only a small portion of the participants (44 people) sampled in this study reported being within 100 miles from the WTC when the attacks occurred, and only 93 people were within the Northeast geographic region. ${ }^{16}$ Thus, these findings provided useful information about short term and very acute reactions following September 11th among a national sample, most of whom were not in close geographic proximity to the WTC.

A larger national study ${ }^{18}$ included assessments that occurred between 1 and 2 months after the attacks with 2,273 adults with over-samples from the NYC metropolitan area $(n=777)$, the Washington, DC, metropolitan area $(n=247)$, and participants from other areas in the US. Study participants were part of a sample contacted prior to September 11th who were involved in a Web enabled study pool through Knowledge Networks. The survey included an assessment of PTSD symptoms specific to the events of September 11th using the full PCL. ${ }^{17}$ The prevalence of probable PTSD in the NYC area was $11.2 \%$ and was significantly higher than the estimated prevalence of PTSD in other major metropolitan areas including Washington, DC, which did not differ from the overall national estimated prevalence of $4.3 \%$. This study importantly showed that PTSD was significantly more prevalent in the New York area than other geographic areas 1-2 months after September 11th. The greater relative geographic isolation of the Pentagon from the city and the military versus civilian identification of the Pentagon may have been factors related to lower threat perception and lower prevalence of PTSD in the general population compared with the NYC metropolitan area. ${ }^{18}$
A subsequent national sample study ${ }^{19}$ assessed acute and longer term symptoms of posttraumatic stress at 9 to 23 days, 2 months, and 6 months after September 11 th. This study also made use of a Knowledge Networks engaged national probability sample of 2729 adults, who represented a subset of a larger sampled panel of $3496.38 \%$ of the sample reported no direct exposure to the attacks, which was defined to include watching the events live on television. An additional $60 \%$ reported watching the events live on television. Only $2 \%$ of the sample were reported to have experienced direct exposure, and $96 \%$ of the sample reported no losses related to the attacks, including knowing someone who was injured or killed, or knowing others who lost property or personally losing property. Thus, this study, unlike the Schlenger and colleagues study, ${ }^{18}$ does not allow for examination of direct exposure factors within a subset of the national sample. This study found that participants reported an average of almost five symptoms of acute PTSD related stress at the initial assessment. At the second wave, the average was four symptoms and by 6 months post-event the average number of symptoms reported was 1.8. Exposure to the events of September 11th, largely defined as live television viewing given the limited actual exposure within the entire sample, was associated with PTSD symptoms 6-months post-event only prior to controlling for coping strategies. The authors concluded that those not directly affected by the attacks also appeared to experience symptomatic reactions to the events. However, conclusions about the impact of direct exposure variables and potential interactions between direct and indirect (eg, television viewing) variables are not possible given the low proportion of respondents in the sample who had direct exposure to the September 11th attacks.

A series of epidemiological studies conducted by our team have focused primarily on the population living in NYC and the surrounding metropolitan area. ${ }^{20-22}$ Thus, these reports allow for examination of potentially important risk factors for PTSD and other mental and behavioral health reactions following September 11th among a population that was likely to feel threatened based on geographic proximity to the attack on the WTC and a subset of whom directly witnessed the events or were directly affected as a result of knowing others who were injured or killed, or who directly lost jobs or possessions in the attacks. This series of studies began with an initial study of 1,008 residents of Manhattan living south of 110th Street conducted 1 month after the attacks. ${ }^{20}$ Two other cross sectional studies were conducted at 4 months after 
the attacks with 2,001 adults who were residents of New York City, and at 6 months after the attacks with 2,752 adult residents of the New York City metropolitan area. ${ }^{22}$ This research team is currently conducting a longitudinal follow-up study with the cohort first assessed 6 months post-September 11th. All of these studies were conducted using random digit dial methods. Structured interview measures used in these studies included the National Women's Study (NWS) PTSD module ${ }^{23}$ for estimation of probable PTSD caseness. The major finding from the initial report by Galea and colleagues ${ }^{20}$ was that $\sim 1$ month after September 11th the prevalence of current (ie, past month) PTSD related to the terrorist attacks was 7.5\% in Manhattan. As noted by Schlenger and colleagues, ${ }^{18}$ this prevalence falls within the $95 \%$ confidence interval for the estimated prevalence of PTSD (11.2\%) that they found in the New York City metropolitan area at a similar time point following the attacks.

More recent reports have focused on functioning through the 6 month period following September 11, 2001. The prevalence of probable PTSD related to September 11th was reported based on the separate cross-sectional surveys conducted at $\sim 1$ month, 4 months, and 6 months post-September 11 th. ${ }^{22}$ The prevalence of estimated current PTSD (ie, past month and related to the September 11th attacks) among those living in Manhattan south of 110th Street was $7.5 \%, 1.7 \%$, and $0.6 \%$ at the three time points. Importantly, lending support to the construct validity of the PTSD measure used in this study, the prevalence of PTSD since the attacks was 37\% among the persons who were reportedly in the building complex during the attacks and 30\% among those who reported sustaining physical injuries during the attacks. This is very similar to the prevalence of PTSD of $34 \%$ observed among direct victims of the Oklahoma City Bombing. ${ }^{24}$ These data suggest a rapid recovery in terms of probable PTSD reactions over time.

\section{POSTTRAUMATIC STRESS DISORDER IN THE GENERAL POPULATION IN ISRAEL}

The studies conducted to examine the prevalence of PTSD following September 11th show fairly consistent results in terms of the prevalence of PTSD in the general New York area population. These data are consistent with findings related to the impact of ongoing terrorist attacks in a recent nationally representative study in Israel..$^{25} \mathrm{~A}$ recent study ${ }^{25}$ assessed symptoms of PTSD and acute distress using the Standford Acute Stress Reaction Questionnaire in the general population of Israel. ${ }^{26}$ Criteria for PTSD were met by $9.4 \%$ of persons interviewed. The authors suggest that these findings are consistent with those of Galea and colleagues ${ }^{20}$ and Schlenger and colleagues ${ }^{18}$ with reported prevalence of PTSD of $7.5 \%$ and $11.2 \%$ among New York residents, respectively. In this sample, PTSD was not significantly predicted by level of exposure (including direct exposure, exposure of family or friends, injury of self, or death or injury of a family member or friend); the authors suggest that this may be seen as consistent with findings of Silver and colleagues and indicate the pervasive population effects of such high impact terrorist events. ${ }^{19}$ Other recent work in Israel ${ }^{27}$ also found a prevalence of "clinically significant PTSD" among $10.1 \%$ of persons in the general population in a convenience sample of Israelis from five cities. We are not aware of research in other countries that has assessed the prevalence of PTSD in the general population after terrorist attacks. Recent research in post-conflict settings like Afghanistan ${ }^{28}$ and Kosovo ${ }^{29}$ suggest that the prevalence of PTSD in these populations is comparable to, or potentially higher than, the prevalence of PTSD in the general population after terrorism discussed here. A full review of PTSD in the post-conflict setting is beyond the scope of this article

\section{POSTTRAUMATIC STRESS DISORDER AMONG PERSONS NOT DIRECTLY AFFECTED BY THE SEPTEMBER 11TH ATTACKS}

The findings discussed here suggest the presence of PTSD in the general population after acts of mass terrorism and raise important questions about the nature of "exposure" to terrorism, and about the nature of PTSD among persons in the general population who may traditionally not be considered to be victims of, or directly affected by, mass traumatic events. In order to further assess the potential differences between persons with PTSD who were or were not directly affected by the September 11th attacks, we carried out several further analyses. Using data from our survey of residents of the New York metropolitan area carried out 6 months after the September 11th attacks $(n=2,752)$, we compared the symptom patterns among persons who were directly or not directly affected by September 11th who met criteria for PTSD related to the attacks in the first 6 months after the attacks in order to assess if the patterns of PTSD observed in these groups were markedly different. For the purposes of these analyses, persons were considered directly affected by the September 11th attacks if they reported that they were in the WTC complex during the attacks, were injured during the attacks, had a friend or relative killed, had possessions lost or damaged, lost a job as a result of the attacks, or were involved in the rescue effort. We 
note that this classification is not meant to be an exact representation of those who were "victims" of the September 11th attacks; such characterization is beyond the scope of our general population survey. Rather, this classification includes variables that are in many ways proxies for substantial burden of exposure to the attacks. We have also considered these analyses using several different categorizations of being directly affected by the attacks (eg, not including persons who lost a job as a result of the attacks); these categorizations all yield results that are not substantively different than those shown here. As expected, persons who were directly affected by the attacks had higher symptom prevalence in all domains (Figure 1). However, importantly, the relative proportions of symptoms in criteria B (re-experiencing), C (avoidance), and D (arousal) were comparable among persons who were directly affected by the attacks and those who were not, with criterion $\mathrm{C}$ being the least prevalent and the diagnostic rate limiting step in both groups. Criterion $\mathrm{C}$ has previously been noted to be the key rate limiting step in diagnosis of PTSD. ${ }^{24}$

Second, we compared the mean number of symptoms among persons who met criteria for PTSD who were and were not directly affected by the September 11th attacks to consider if persons with PTSD but with different exposures to the disaster had substantially different symptom burden. Only mean number of avoidance symptoms (4.4 versus $3.8, P=.02$ ) was significantly different when comparing persons with PTSD who were and were not directly affected by the disaster (Figure 2). This provides little evidence for substantially different burden of symptoms of PTSD between persons who were or were not directly affected by the disaster. We note that we did not assess the phenomenology of PTSD symptoms in our surveys; further work would do well to assess differences in symptom content and quality (eg, content of participants' intrusive recollections) between those who were directly or indirectly affected by mass terrorist incidents.

The Diagnostic and Statistical Manual of Mental Disorder, Fourth Edition (DSM-IV) requires that in addition to expressing the required PTSD symptoms, persons with the disorder must also exhibit clinically significant distress and impairment. ${ }^{30}$ Therefore, it is plausible that the observation of PTSD among persons who were not directly affected is an artifact of the method of assessment of PTSD in this work (ie, the use of a lay-administered telephone instrument assessing symptoms of PTSD). After Shalev and colleagues, ${ }^{31}$ we reassessed the prevalence of PTSD in our sample adding measures to assess distress and functional limitation to the PTSD symptoms. In order to assess distress we required that persons reported fear, helplessness, or horror at the time of the September 11th attacks and in order to assess functional limitation we required that persons report that their PTSD symptoms were interfering with their daily life. Thus we were able to compare prevalence of PTSD with and without inclusion of DSM-IV Criterion A2 (reactions of acute distress) and Criterion F (functional impairment). Overall, as shown in Figure 3, the prevalence of PTSD as measured by the NWS instrument in our survey was $6.0 \%$. 5.4\% of persons reported PTSD and acute distress, 3.2\% reported PTSD and functional limitation, and $2.9 \%$ reported PTSD, acute distress, and dysfunction.

Thus, in our sample, $~ 50 \%$ of individuals who had enough PTSD symptoms to quality for a PTSD diagnosis using the NWS PTSD module also experienced distress and dysfunction, in order to "meet" diagnostic criteria for PTSD. This pattern (ie, the recognition that adding functional limitations to symptom-based diagnostic criteria reduces the prevalence of PTSD) has been reported for other lay-administered instruments that assess PTSD symptoms. In a similar analysis, only $22 \%$ of subjects in two Israeli communities who met symptom criteria for PTSD using the PTSD Symptom

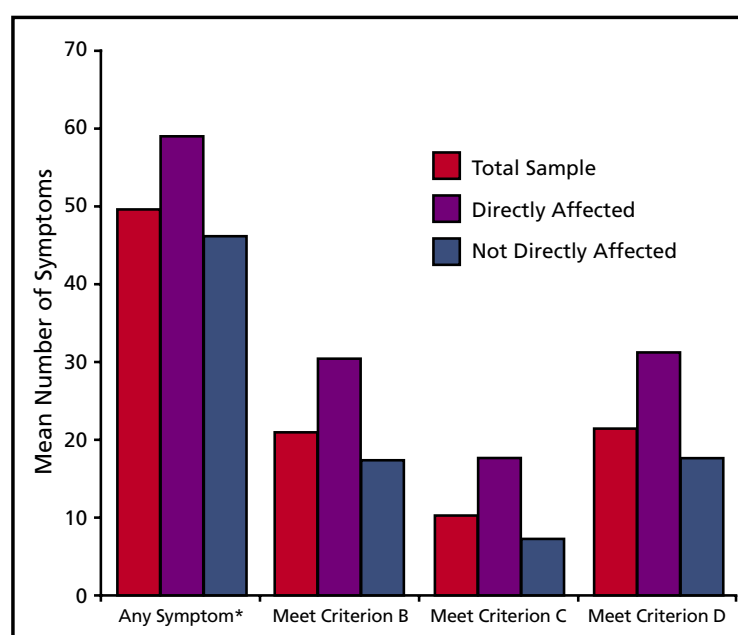

FIGURE 1. Patterns of posttraumatic stress symptoms among persons in the New York City metropolitan area in the first 6 months after September 11, $2001(\mathrm{~N}=2,752)$.

* Any symptom refers to the prevalence of any PTSD symptom. Meeting criteria $B, C$, or D refers to the prevalence of persons having sufficient symptoms to meet DSM-IV criteria for re-experiencing (B), avoidance (C), or arousal (D) symptom domains. For the purposes of these analyses, persons were considered directly affected by the September 11th attacks if they were in the WTC complex during the attacks, were injured during the attacks, had a friend or relative killed, possessions lost or damaged, or lost a job as a result of the attacks, or were involved in the rescue effort.

PTSD=posttraumatic stress disorder; $D S M-I V=$ Diagnostic and Statistical Manual of Mental Disorders, Fourth Edtion; WTC $=$ World Trade Center.

Galea S, Resnick H. CNS Spectr. Vol 10, No 2. 2005. 
Scale also met criteria for distress and dysfunction..$^{31}$ The higher proportion of persons meeting NWS symptom criteria who also had distress and dysfunction may be a reflection of the fact that the NWS is probably a conservative symptom-based assessment of PTSD. A comparison of estimated cases based on the NWS measure and caseness based on the PCL within a sub-sample of 229 participants in our survey conducted 4 months after September 11th indicated that each measure had high associated Cronbach's $\alpha$ ( 0.87 and 0.88 , respectively), and that in a receiver operating characteristic analysis using a PCL cutoff of $\geq 50$, the PCL optimally predicted PTSD diagnosis using the NWS PTSD module with an area under the curve of 0.97 . The PCL had $75 \%$ sensitivity and 95\% specificity in detecting probable PTSD cases based on the NWS PTSD module. Therefore, the NWS likely is a more conservative assessment instrument than the PCL, an observation that may reconcile the slightly higher prevalence of PTSD documented in New York City by Schlenger and colleagues ${ }^{18}$ compared with Galea and colleagues ${ }^{20}$

However, importantly for this discussion, we were interested in assessing if there were appreciable differences in the prevalence of PTSD combined with distress and dysfunction among persons who were directly affected by the disaster or those who were not. As

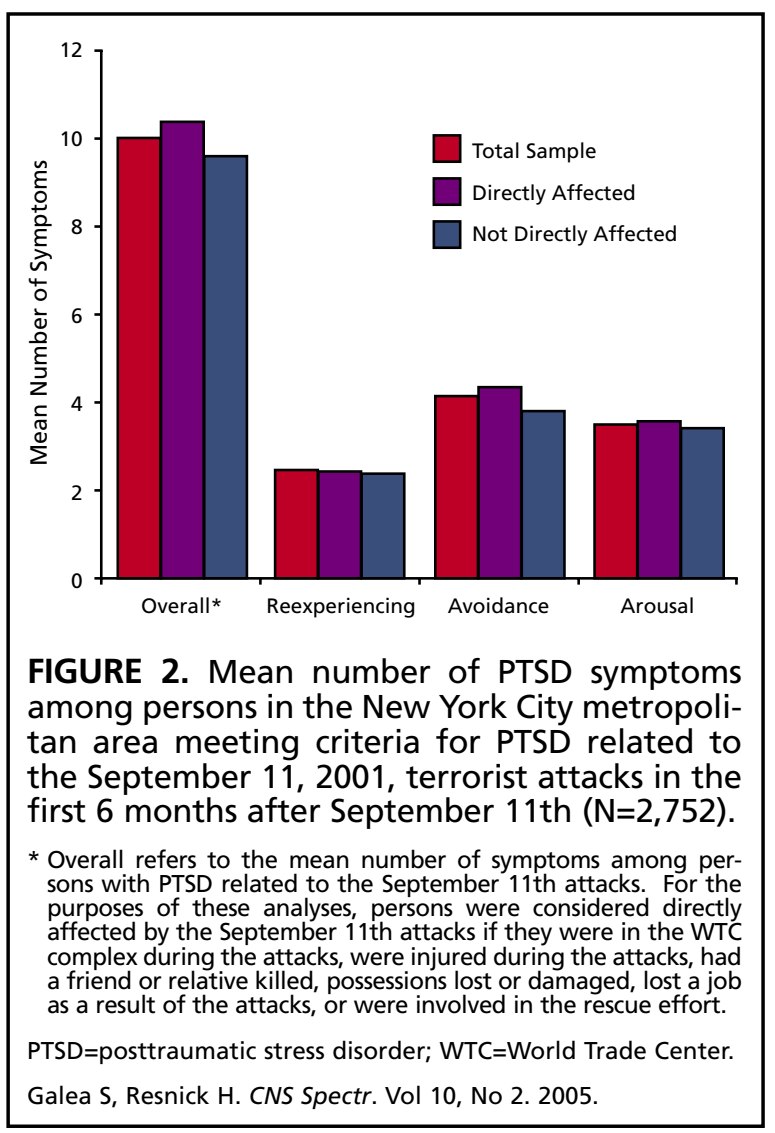

shown in Figure 4, the mean number of symptoms in this more restrictive group of participants is higher than the mean number of symptoms among persons meeting only symptom criteria for PTSD, as would be expected. Also, persons who were directly affected only had a significantly different number of arousal symptoms (3.9 versus $3.2 ; P=.03$ ) compared with persons who were not directly affected by the disaster. Congruent with the observation among persons meeting NWS PTSD criteria (Figure 2) this suggests little difference in symptom burden among persons who were directly or indirectly exposed to the September 11th attacks, suggesting that using more restrictive definitions of PTSD do not alter the fundamental observation of a burden of PTSD, and its specific symptom patterns, among persons who were indirectly affected by the disaster.

\section{THE NATURE OF GENERAL POPULATION "EXPOSURE" TO MASS TERRORIST INCIDENTS}

In the New York City metropolitan area that was the sampling frame for our studies, there are $\sim 13.5$ million adults. ${ }^{32}$ We estimate that $28.3 \%$ of persons in this sampling frame could be considered directly affected by the attacks. Analyses from our studies suggest that the prevalence of PTSD in the first 6 months after September 11 th was $\sim 6 \%$ overall in the area, $12 \%$

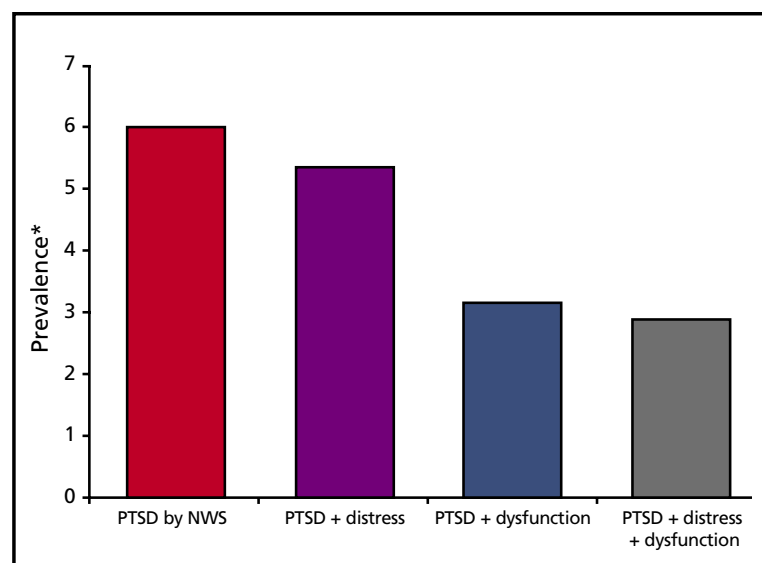

FIGURE 3. Prevalence of PTSD related to the September 11, 2001, attacks among persons in the New York City metropolitan area in the first 6 months after September 11th using different threshold criteria $(\mathrm{N}=2,752)$.

* Bars refer to prevalence of participants reporting full criteria for PTSD using NWS PTSD criteria; percentage of participants reporting NWS PTSD criteria and significant distress during the September 11 attacks; percentage of persons reporting NWS PTSD criteria and related functional limitation; and prevalence of participants reporting NWS PTSD criteria, distress, and functional limitation.

PTSD=posttraumatic stress disorder; NSW=National Women's Study.

Galea S, Resnick H. CNS Spectr. Vol 10, No 2. 2005. 
in the directly affected group and about $3.7 \%$ in the not directly affected group. Simple calculations then show that the net burden of probable PTSD in the directly affected group $(13,500,000 \times 0.283 \times 0.12)$ would be expected to be $\sim 460,000$ and in the not directly affected group $(13,500,000 \times 0.717 \times 0.037)$ would be $\sim 360,000$ (Figure 5). While this calculation is meant to be merely illustrative and not a definite assessment of the number of people who had psychopathology, it demonstrates that the net burden of psychopathology in the aftermath of a terrorist incident in a densely populated urban area may be as high among persons who are not directly affected by the disaster as it is among those who are directly affected. Calculations using different definitions of what constituted being directly affected by the attacks (eg, different combinations of whether respondents saw events in person, lost relatives or friends etc) yield similar results.

This observation is controversial in the context of the discussion about what constitutes exposure for PTSD, and by extension, what constitutes PTSD itself. The implication of this thinking is that from a popu-

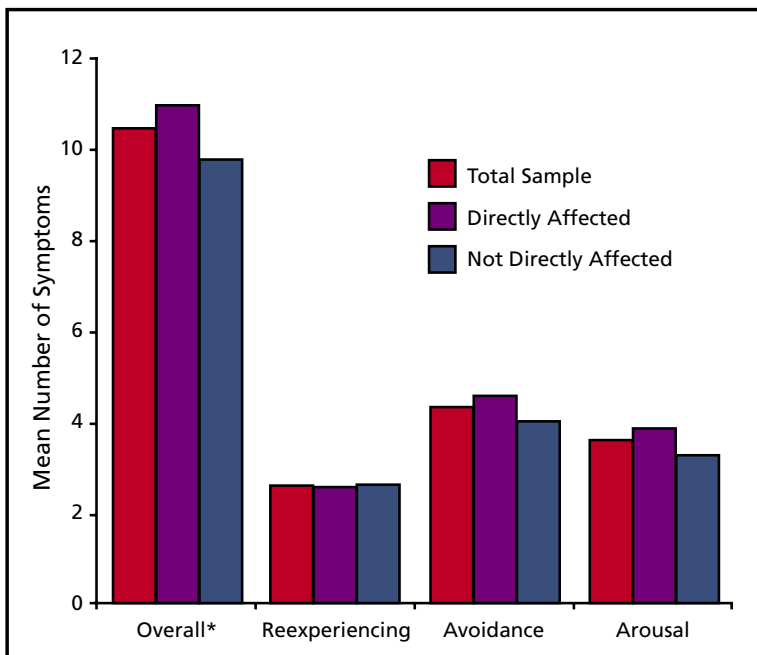

FIGURE 4. Mean number of PTSD symptoms among persons in the New York City metropolitan area meeting restrictive criteria for PTSD related to the September 11, 2001, attacks in the first 6 months after September 11 th $(\mathrm{N}=2,752)$.

* Overall refers to the mean number of symptoms among persons with PTSD related to the September 11 th attacks determined using restrictive criteria. Restrictive criteria for PTSD refers to persons meeting criteria for NSW PTSD symptoms, analyses, persons were considered directly affected by the September 11 th attacks if they were in the WTC complex during the attacks, were injured during the attacks, had a friend or relative killed, possessions lost or damaged, lost a job as a result of the attacks, or were involved in the rescue effort.

PTSD=posttraumatic stress disorder; NSW=National Women's Study; WTC=World Trade Center.

Galea S, Resnick H. CNS Spectr. Vol 10, No 2. 2005. lation perspective, particularly in terrorist attacks in densely populated urban areas, persons who are less directly affected by a terrorist attack may actually bear the brunt of the psychopathology in a population. It is important to note that this discussion of the population burden of psychopathology is premised on two observations. First, although persons who are more exposed to terrorism are substantially more likely to have postdisaster psychopathology, this group is small relative to the general population. Second, the prevalence of posttraumatic stress symptoms in the general population of persons not directly affected by an event is not zero. While the first of these observations is uncontroversial, the second may be more controversial.

Why should persons in the general population (ie, who were not directly affected by the disaster) be exposed to the mass trauma? The DSM-IV diagnostic definition of PTSD requires that a person "experienced, witnessed, or was confronted with an event or events that involved... a threat to the physical integrity of self or others" (criterion A1) and that the person have a subjective experience of "fear, helplessness, or horror" (Criterion A2). ${ }^{30}$

On September 11th and during the difficult days afterwards there were many reasons for residents of the New York City metropolitan area to fear that their personal safety was under threat, to be confronted by the attacks, and to experience helplessness or horror, even if they were not directly affected on the morning of September 11 th. In

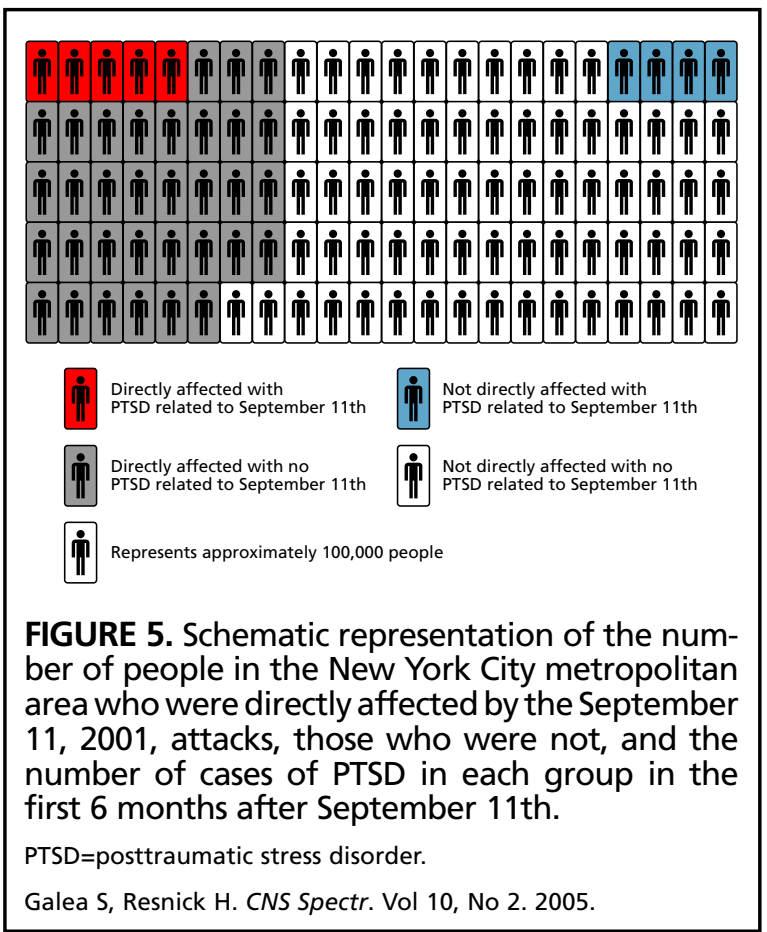


the context of the September 11 th attacks, persons who were not directly affected by the attacks may have been aware of the attacks through the media, word-of-mouth, and communication with friends or family who were present for the attacks and who subsequently suffered posttraumatic stress symptoms. In addition, during the attacks, it was unclear for many in New York City whether other attacks were forthcoming; "fog of war" rumors were common on September 11th and, in many ways, residents of New York City felt under attack all day. Our results then argue that these exposures may have been sufficient for "indirectly affected" residents of the New York City metropolitan area to experience the attacks and to subsequently suffer substantial posttraumatic psychopathology. Further work by our group in fact has shown that while the prevalence of PTSD after the September 11th terrorist attacks was high throughout New York City, it was substantially lower in the suburbs of New York City than it was in the city proper, ${ }^{33}$ suggesting that city residence itself was an exposure to the attacks and reinforcing our suggestion that the persons in New York City who were not directly affected by the attacks were still exposed, albeit indirectly, to the helplessness and horror of September 11th and to the plausible fear that they too were at risk from the attacks. Congruent with this observation, the findings of Schlenger and colleagues strongly suggest that those who lived in the New York City area were different from those in the rest of the nation in terms of their responses to September 11 th. ${ }^{18}$ We also suggest that the recent findings from Israel, ${ }^{25}$ showing the nationwide impact of the suicide bombings, may be more consistent with findings in the New York City geographic area specifically than with those in the US population more broadly. The nation of Israel covers a relatively small geographic area and all citizens may be likely to perceive greater realistic risk from such attacks. In addition, multiple attacks have occurred in Israel in multiple geographic areas making risk more salient regardless of location. This is more similar to the situation for residents of New York City during the September 11th attacks who may have reasonably estimated personal threat to be greater than those in the US living in areas much more distant from the attacks on the WTC. The published literature then suggests that the population residing in New York City and the surrounding metropolitan area was particularly at risk for PTSD in the months following the attacks, while those in the rest of the nation may have experienced some more transient general distress and stress symptoms during the initial days following the attacks.

In considering potential exposures to terrorist incidents for persons in the general population, the observations in several post-September 11th studies about a correlation between PTSD and media exposure are intriguing, ${ }^{34,35}$ and additional work needs to focus on potential unique and interactive effects of media coverage among those with varying levels of direct or indirect exposure and how it may be associated with PTSD or other distress. If media exposure were to constitute an independent traumatic risk for the incidence of PTSD, it could have dramatic implications for the consequences of highly televised mass traumatic events in future. Such research should also focus on exposure to information and potential threats occurring over time subsequent to the disaster event. Strategies designed to increase our understanding of patterns of occurrence of distress and increased media viewing would be helpful.

Although a full discussion of the risk factors associated with PTSD among those who were directly affected by and those who were not directly affected by the September 11th attacks is beyond the scope of this review (data to this effect has been published previously $\mathrm{y}^{20-22}$ ), we note that it is likely that there are several groups of persons who may be more vulnerable to the development of psychopathology after terrorist events and who may constitute a substantial proportion of those in the indirectly affected general population who subsequently develop PTSD. For example, the presence of previous psychopathology is a risk factor for subsequent development of PTSD. National surveys have shown that up to $50 \%$ of person in the general population report at least one lifetime psychiatric disorder, and close to $30 \%$ report at least one 12 month disorder. ${ }^{36}$ In our studies, the presence of prior stressors, including prior mental health problems, was an important predictor of PTSD among both persons who were directly and those indirectly exposed to PTSD. ${ }^{20}$ Therefore, specific groups are likely to bear a disproportionate of PTSD among those indirectly affected by mass terrorism.

\section{CONCLUSION}

Several epidemiological studies were conducted in the aftermath of the September 11th attacks that made use of standardized assessment measures that allowed for good comparability across studies and that included design variations enabling observations about different segments of the US and New York City area populations. These studies identified an elevated prevalence of PTSD in the general population in the first months 
after the attacks. Debate about the exact array of symptoms that constitute PTSD, and whether PTSD would best be characterized as a categorical or a dimensional disorder ${ }^{37}$ continues and there is little doubt that what constitutes a diagnosis of PTSD will change in subsequent editions of the Diagnostic and Statistical Manual of Mental Disorders. The data from the general population after September 11th suggest that it is likely that a wide range of experiences, beyond those that are considered extreme traumatic events by DSM-IV criteria, are capable of producing PTSD symptoms. ${ }^{3,38}$ Future research should consider carefully assessing the range of exposures faced by persons in the general population after a mass disaster and the mechanisms through which persons in the general population may be at risk for PTSD. Such research has potential to guide intervention and reduce the burden of PTSD in the general population after terrorist attacks. CNS

\section{REFERENCES}

1. Norris FH. Epidemiology of trauma: frequency and impact of different potentially traumatic events on different demographic groups. J Consult Clin Psychol. 1992;60:409-418.

2. Breslau N, Davis GC, Andreski P, Peterson E. Traumatic events and posttraumatic stress disorder in an urban population of young adults. Arch Gen Psychiatry. 1991;48:216-222.

3. Resnick HS, Kilpatrick DG, Dansky BS, Saunders BE, Best CL. Prevalence of civilian trauma and posttraumatic stress disorder in a representative national sample of women. J Consult Clin Psychol. 1993;61:984-991.

4. Kessler RC, Sonnega A, Bromet E, Hughes M, Nelson CB. Posttraumatic stress disorder in the National Comorbidity Survey. Arch Gen Psychiatry. 1995;52:1048-1060.

5. Breslau N, Kessler RC, Chilcoat HD, Schultz LR, Davis GC, Andreski P. Trauma and posttraumatic stress disorder in the community: the 1996 Detroit Area Survey of Trauma. Arch Gen Psychiatry. 1998;55:626-632.

6. Kessler RC. Posttraumatic stress disorder: the burden to the individual and to society. J Clin Psychiatry 2000;61(suppl 5):4-12.

7. Corradi J, Fagen PW, Garreton M. Fear at the Edge: State Terror and Resistance in Latin America. Berkeley, Calif: University of California Press; 1992.

8. Nordstrom C, Martin J. The Paths to Domination, Resistance, and Terror. Berkeley, Calif: University of California Press; 1992.

9. Burkle FM Jr. Acute-phase mental health consequences of disasters: implications for triage and emergency medical services. Ann Emerg Med. 1996;28:119-128.

10. Norris FH, Friedman MJ, Watson PJ, Byrne CM, Diaz E, Kaniasty K. 60,000 disaster victims speak: Part I. An empirical review of the empirical literature, 1981-2001. Psychiatry. 2002;65:207-239.

11. Tucker P, Boehler SD, Dickson W, Lensgraf SJ, Jones D. Mental health response to the Oklahoma City bombing. J Okla State Med Assoc. 1999;92:168-171.

12. Smith DW, Christiansen EH, Vincent R, Hann NE. Population effects of the bombing of Oklahoma City. J Okla State Med Assoc. 1999;92:193-198.

13. Sprang G. Post-Disaster Stress Following the Oklahoma City Bombing: an examination of three community groups. J Interper Violence. 1999;14:169-183.

14. Pfefferbaum B, Nixon SJ, Tivis RD, et al. Television exposure in children after a terrorist incident. Psychiatry. 2001;64:202-211.

15. Pfefferbaum BB, Nixon SJ, Tucker PM, et al. Posttraumatic stress responses in bereaved children after the Oklahoma City bombing. J Am Acad Child Adolesc Psychiatry. 1999;38:1372-1379.
16. Schuster MA, Stein BD, Jaycox LH, et al. A national survey of stress reactions after the September 11, 2001, terrorist attacks. New Engl J Med. 2001;345:1507-1512.

17. Weathers FW, Litz BT, Herman DS, Huska JA, Keane TM. The PTSD Checklist (PCL): reliability, validity, and diagnostic utility. Paper presented at: annual meeting of the International Society for Traumatic Stress Studies. San Antonio, Tex, October 24-27, 1993.

18. Schlenger WE, Caddell JM, Ebert L, et al. Psychological reactions to terrorist attacks: findings from the National Study of Americans' Reactions to September 11. JAMA. 2002;288:581-588.

19. Silver RC, Holman EA, McIntosh DN, Poulin M, Gil-Rivas V. Nationwide Longitudinal Study of Psychological Responses to September 11. JAMA. 2002;288:1235-1244.

20. Galea S, Ahern J, Resnick H, Kilpatrick D, Bucuvalas M, Gold J, Vlahov D. Psychological sequelae of the September 11th attacks in Manhattan, New York City. N Engl J Med. 2002; 346:982-987.

21. Vlahov D, Galea S, Resnick H, et al. Increased consumption of cigarettes, alcohol and marijuana among manhattan residents after the September 11th terrorist attacks. Am J Epidemiol. 2002;555:988-996.

22. Galea S, Vlahov D, Resnick H, et al. Trends of probable post-traumatic stress disorder in New York City after the September 11 terrorist attacks. Am J Epidemiol. 2003;158:514-524.

23. Kilpatrick DG, Acierno R, Schnurr PP, Saunders B, Resnick HS, Best CL. Risk factors for adolescent substance abuse and dependence: data from a national sample. J Consult Clin Psychol. 2000;68:19-30.

24. North CS, Nixon SJ, Shariat S, et al. Psychiatric disorders among survivors of the Oklahoma City bombing. JAMA. 1999;282:755-762.

25. Bleich A, Gelkopf M, Solomon Z. Exposure to terrorism, stress-related mental health symptoms, and coping behaviors among a nationally representative sample in Israel. JAMA. 2003;290:612-620.

26. Cardena E, Koopman C, Classen C, Waelde LC, Spiegel D. Psychometric properties of the Stanford Acute Reaction Questionnaire (SASRQ). J Trauma Stress. 2000;13:719-734.

27. Gidron Y, Kaplan Y, Velt As, Shalem R. Prevalence and moderators of terror-related posttraumatic stress disorder symptoms in Israeli citizens. Isr Med Assoc J. 2004;6:387-391.

28. Scholte WF, Olff M, Ventevogel P, de Vries GJ, Jansveld E, Cardozo BL, Crawford CA. Mental health symptoms following war and repression in eastern Afghanistan. JAMA. 2004:292:585-593.

29. Fernandez WG, Galea S, Ahern J, Sisco S, Waldman RJ, Koci B, Vlahov D. Mental health status among ethnic Albanians seeking medical care in an emergency department two years after the war in Kosovo: a pilot project. Ann Emerg Med. 2004;43:E1-E8.

30. Diagnostic and Statistical Manual of Mental Disorders. 4th ed. Washington, DC: American Psychiatric Association; 1994.

31. Shalev AY, Tuval-Mashiach R, Hadar H. Posttraumatic stress disorder as a result of mass trauma. J Clin Psychiatry. 2004;65(suppl 1):4-10.

32. Bureau of the Census. Census Summary Tape, File 3A (STF3A). Washington, DC: US Dept of Commerce; 2000.

33. Galea S, Boscarino J, Resnick H, Vlahov D. Mental health in New York City after the September 11 terrorist attacks: results from two population surveys. In: RW Manderscheid R, Henderson MJ, eds. Mental Health, United States, 2002. Washington, DC: US Government Print Office; 2003.

34. Ahern J, Galea S, Resnick H, Vlahov D. Television images and probable posttraumatic stress disorder after September 11: the role of background characteristics, event exposures, and perievent panic. J Nerv Ment Dis. 2004;192:217-226.

35. Ahern J, Galea S, Resnick H, Kilpatrick D, Bucuvalas M, Vlahov D. Television images and psychological symptoms after the September 11 terrorist attacks. Psychiatry. 2002;65:289-300.

36. Kessler RC, McGonagle KA, Zhao S, et al. Lifetime and 12-month prevalence of DSM-III-R psychiatric disorders in the United States. Results from the National Comorbidity Survey. Arch Gen Psychiatry. 1994;51:8-19.

37. Shalev AY. What is posttraumatic stress disorder? J Clin Psychiatry. 2001;62(suppl 17):4-10.

38. Solomon SD, Canino GJ. Appropriateness of DSM-III-R criteria for posttraumatic stress disorder. Compr Psychiatry. 1990;31:227-237. 